\title{
Tralokinumab for the treatment of severe, uncontrolled asthma: the ATMOSPHERE clinical development program
}

\author{
Reynold A Panettieri Jr*,1, Millie Wang², Martin Braddock², Karin Bowen ${ }^{3}$ \& Gene Colice \\ ${ }^{1}$ Rutgers Institute for Translational Medicine \& Science, Rutgers, The State University of New Jersey, NJ 08901, USA \\ ${ }^{2}$ Global Medicines Development, AstraZeneca, Cambridge, UK \\ ${ }^{3}$ Global Medicines Development, AstraZeneca, Gaithersburg, MD 20878, USA \\ * Author for correspondence: Tel.: +1 732235 6404; Fax: +1 732235 7178; rp856@rbhs.rutgers.edu
}

Tralokinumab, a fully human $\operatorname{lgG}_{4}$ monoclonal antibody, specifically neutralizes IL-13. The ATMOSPHERE clinical development program comprised four randomized, placebo-controlled clinical trials and an openlabel study that aimed to assess the efficacy and safety of tralokinumab for the treatment of severe, uncontrolled asthma. The two pivotal trials (STRATOS 1 and STRATOS 2; NCT02161757 and NCT02194699) evaluated the efficacy and safety of tralokinumab, with STRATOS 1 identifying a subgroup most likely to demonstrate enhanced response to treatment. Further trials have assessed the ability of tralokinumab to reduce oral corticosteroid use (TROPOS; NCT02281357) and determined its mechanistic effects (MESOS; NCT02449473). An open-label study in Japanese individuals (NCT02902809) assessed the long-term safety and tolerability of tralokinumab in this population.

First draft submitted: 20 December 2017; Accepted for publication: 16 February 2018; Published online: 14 March 2018

Keywords: airway obstruction $\bullet$ anti-IL-13 $\bullet$ biomarkers $\bullet$ MESOS $\bullet$ monoclonal antibody $\bullet$ severe asthma $\bullet$ STRATOS 1 • STRATOS 2 • TROPOS

\section{Severe asthma overview}

Asthma, an inflammatory airway disease, affects approximately 300 million people worldwide [1] and manifests as variable respiratory symptoms (wheeze, shortness of breath, chest tightness and/or cough) and airflow limitation [2]. Approximately $5-10 \%$ of people with asthma have severe disease [3] defined as asthma that requires high-dosage inhaled corticosteroids (ICS) plus long-acting $\beta_{2}$ agonists (LABA) to prevent it from becoming uncontrolled, or asthma that remains uncontrolled despite treatment [2]. The treatment of people with severe asthma remains a significant unmet need. These individuals may require episodic treatment with oral corticosteroids (OCS) to manage exacerbations and they may become reliant on daily OCS to control their disease. Long-term OCS use is associated with a wide variety of serious adverse effects, such as osteoporosis, elevated risk of infections, and cardiovascular, metabolic and psychiatric complications that increase healthcare resource use and associated costs $[2,4,5]$. Some people with severe asthma continue to experience disease impairment, despite OCS use, and are at greater risk for future exacerbations compared with those not receiving daily OCS [6].

Asthma manifests as a heterogeneous disease, both clinically and pathophysiologically, with multiple phenotypes, defined by specific demographic and clinical characteristics that can affect response to treatment. In addition, the underlying mediators of airway inflammation can vary. This is a critically important point as we progress toward a precision medicine approach to the care of people with severe asthma because if the specific mediators of airway inflammation in asthma are identified, then plausibly we could target such mechanisms with specific therapies [2,7]. Conceivably, targeted treatments, such as biologics, can be added to standard therapy with ICS/LABA to more effectively treat severe asthma [7]. Type-2-mediated inflammation represents an important feature of asthma pathophysiology and the underlying features of type-2-mediated asthma require activation of cytokines IL-4, -5 and $-13[8]$. In a study using bronchoscopy to biopsy the airways of people with mild to moderate asthma, Woodruff $e t$ al. found that 22 of the 42 participants studied had evidence of overexpression of IL-13-induced epithelial genes coding for CLCA1, periostin, and SERPINB2 [9]. Increased expression of mRNA for IL-13 
has been detected in bronchial biopsies of people with asthma [10,11], while increased concentrations of IL-13 have been found in the sputum of corticosteroid-naive people with asthma compared with those who had received corticosteroids [12]. These data suggest a role for the pleiotropic cytokine IL-13 in the pathophysiology of asthma [9]. The effects of IL-13 include goblet cell hyperplasia and increased mucus production, fibrosis, airway remodeling, airway hyper-responsiveness, and IgE synthesis [13-18]. Recognizing the possible importance of IL-13 in mediating asthma prompted the development of anti-IL-13 biologics, such as tralokinumab.

\section{Background to tralokinumab}

IL-13 initiates cytosolic signaling by binding to IL-13R $\alpha 1$ that then recruits IL-4R $\alpha$ to form a heterodimeric receptor complex and induces downstream effects that contribute to the pathophysiology of certain types of asthma [19]. IL-13 also binds to IL-13R $\alpha 2$ that acts as a decoy receptor and is most likely involved in fibrosis [20]. Tralokinumab, a fully human $\mathrm{IgG}_{4}$ monoclonal antibody, effectively and specifically neutralizes IL-13, preventing interaction of the cytokine with the IL-13R $\alpha 1$ and $\alpha 2$ subunits (Figure 1) [21,22].

Tralokinumab has been studied in people with asthma in three Phase II trials (NCT00640016, NCT00873860 [23], and NCT01402986 [24]), one of which was stopped early due to poor participant recruitment. In the all-comers participant populations, neither of the fully enrolled Phase II studies (NCT00873860 and NCT01402986) met their primary endpoints [23,24]. In both Phase II trials, however, IL-13 blockade with tralokinumab improved lung function in the all-comers population of participants with moderate to severe asthma inadequately controlled with medium- or high-dosage ICS/LABA $[23,24]$. In post hoc analyses of the two trials, an interesting pattern suggestive of a tralokinumab benefit was seen preferentially in participants with evidence of IL-13 activation [23,24]. In the Phase IIa study (NCT00873860), in a subgroup of participants with moderate to severe, uncontrolled asthma who had increased sputum concentrations of IL-13 at baseline, there were trends for tralokinumab treatment to have clinically meaningful improvements in markers of asthma control (Asthma Control Questionnaire [ACQ]-6), as well as in the forced expiratory volume in $1 \mathrm{~s}\left(\mathrm{FEV}_{1}\right)$ compared with placebo [23]. As it was not practical to collect sputum in larger trials, in the Phase IIb study (NCT01402986), blood concentrations of periostin and DPP-4 served as biomarkers of IL-13 activation [24]. In post hoc analyses of this study, subgroups of participants with severe, uncontrolled asthma who had $\mathrm{FEV}_{1}$ reversibility $\geq 12 \%$, were not receiving regular OCS at study entry, and had elevated concentrations of DPP-4 or periostin at baseline, tralokinumab (300 mg subcutaneously [SC] every 2 weeks [Q2W]) demonstrated improvements in lung function, exacerbations, asthma symptoms and quality of life [24]. No safety signals of concern were observed in these Phase II studies. In the Phase IIa study, there were no serious adverse events (AEs) considered to be related to study medication in participants who received tralokinumab [23], while in the Phase IIb study, the incidence of treatment-emergent AEs was similar between the tralokinumab and placebo groups [24].

An integrated pharmacokinetics (PK)-pharmacodynamic model interrogated the Phase II data to select the most appropriate tralokinumab dosage to be used in Phase III trials. As near-maximal increase in $\mathrm{FEV}_{1}$ was predicted at a dosage of $300 \mathrm{mg} \mathrm{SC} \mathrm{Q2W}$, this dosage of tralokinumab was selected for the Phase III trials [25]. In addition, based on population PK modeling, weight-based dosing or dose adjustments of tralokinumab are not required for use in adolescents [26] or people of Japanese ethnicity.

\section{Objective of the review}

The objective of this review is to provide a rationale for, and a summary of, the tralokinumab late-stage clinical development program and highlight the value of utilizing biomarkers of IL-13-driven disease in the clinical management of severe, uncontrolled asthma.

\section{The ATMOSPHERE program: late-stage clinical development of tralokinumab}

Tralokinumab was in late-stage clinical development for the treatment of people with severe, uncontrolled asthma. The ATMOSPHERE clinical program consisted of five clinical trials: STRATOS 1 (NCT02161757 [27]), STRATOS 2 (NCT02194699 [27]), TROPOS (NCT02281357 [28]), MESOS (NCT02449473 [29]) and a long-term trial in Japanese people (NCT02902809), involving a total of 2310 participants, aged 12-75 years, across 27 countries (Table 1). 


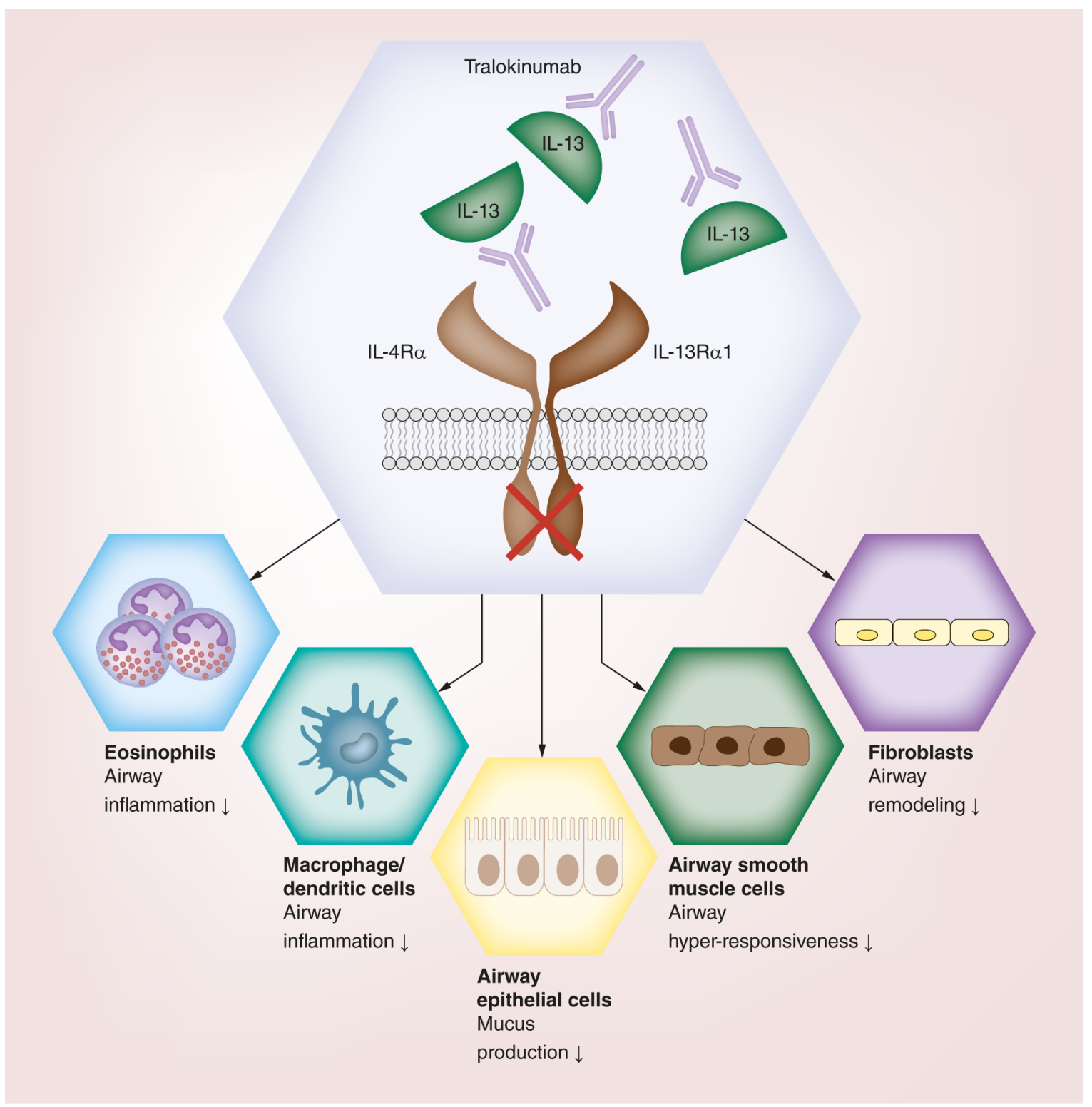

Figure 1. Tralokinumab mechanism of action.

Tralokinumab binds to IL-13 preventing its interaction with both IL-13R $\alpha 1$ and IL-13R $\alpha 2$, which in turn results in inhibition of IL-13 signaling. IL-13 signaling is initiated through binding to IL-13R $\alpha$, which then recruits IL-4R $\alpha$ forming a heterodimeric receptor complex and inducing downstream effects. Downstream biological processes mediated by IL-13 signaling include airway inflammation, mucus production, airway hyper-responsiveness, and airway remodeling.

\section{The STRATOS 1 \& STRATOS 2 studies}

\section{Rationale for studies}

The Phase II segment of a clinical development program aims to answer key questions about a drug's efficacy profile, particularly what participant populations could potentially derive clinical benefit. This was not the case with tralokinumab since the primary efficacy outcome measure was not met in the all-comers population in the two completed Phase II studies (improvement in asthma control in the Phase IIa study [23]; reduction in the annualized asthma exacerbation rate [AAER] in the Phase IIb study [24]). However, there were indications in both studies that a subgroup of participants with evidence of IL-13 axis activation could benefit from tralokinumab treatment. In the Phase IIa and IIb studies, participants with increased sputum concentrations of IL-13 and with increased blood concentrations of periostin and DPP-4 (biomarkers of activated IL-13), respectively, achieved improved 


\begin{tabular}{|c|c|c|c|c|c|}
\hline & STRATOS 1 [27] & STRATOS 2 [27] & TROPOS [28] & MESOS [29] & Japanese LTS \\
\hline Number of participants & 1207 & 856 & 140 & 79 & 28 \\
\hline Run-in period & 4-6 weeks & 4-6 weeks & 2 weeks & - & $\leq 2$ weeks \\
\hline Treatment period & 52 weeks & 52 weeks & 40 weeks & 12 weeks & 52 weeks \\
\hline Follow-up period & 20 weeks & 20 weeks & 14 weeks & 14 weeks & 14 weeks \\
\hline Participant population & $\begin{array}{l}\text { Participants with asthma } \\
\text { inadequately controlled } \\
\text { with ICS/LABA }\end{array}$ & $\begin{array}{l}\text { Participants with asthma } \\
\text { inadequately controlled } \\
\text { with ICS/LABA }\end{array}$ & $\begin{array}{l}\text { Participants with asthma } \\
\text { who require maintenance } \\
\text { OCS in addition to } \\
\text { ICS/LABA }\end{array}$ & $\begin{array}{l}\text { Participants with asthma } \\
\text { inadequately controlled } \\
\text { with ICS }\end{array}$ & $\begin{array}{l}\text { Japanese participants with } \\
\text { asthma inadequately } \\
\text { controlled with ICS/LABA }\end{array}$ \\
\hline Tralokinumab dosage & $\begin{array}{l}300 \mathrm{mg} \text { SC Q2W or } \\
300 \mathrm{mg} \text { SC Q4W }\end{array}$ & $300 \mathrm{mg} \mathrm{SC}$ Q2W & $300 \mathrm{mg} \mathrm{SC}$ Q2W & $300 \mathrm{mg} \mathrm{SC}$ Q2W & $300 \mathrm{mg} \mathrm{SC}$ Q2W \\
\hline Comparator & Placebo SC Q4W & Placebo SC Q2W & Placebo SC Q2W & Placebo SC Q2W & - \\
\hline Primary objective & $\begin{array}{l}\text { Assess efficacy and safety } \\
\text { of tralokinumab in } \\
\text { all-comers population } \\
\text { and identify } \\
\text { biomarker-positive } \\
\text { subgroup }\end{array}$ & $\begin{array}{l}\text { Validate efficacy and } \\
\text { safety of tralokinumab in } \\
\text { biomarker-positive } \\
\text { subgroup }\end{array}$ & $\begin{array}{l}\text { Assess effect of } \\
\text { tralokinumab on } \\
\text { reducing the OCS dosage }\end{array}$ & $\begin{array}{l}\text { Assess effect of } \\
\text { tralokinumab on } \\
\text { eosinophilic airway } \\
\text { inflammation and } \\
\text { remodeling }\end{array}$ & $\begin{array}{l}\text { Assess long-term safety and } \\
\text { tolerability of tralokinumab } \\
\text { in Japanese participants }\end{array}$ \\
\hline Primary outcome measure & AAER up to week 52 & AAER up to week 52 & $\begin{array}{l}\text { Percentage change from } \\
\text { baseline in average OCS } \\
\text { dose at week } 40\end{array}$ & $\begin{array}{l}\text { Change in number of } \\
\text { airway submucosal } \\
\text { eosinophils per } \mathrm{mm}^{2} \text { from } \\
\text { baseline to week } 12\end{array}$ & $\begin{array}{l}\text { Number of AEs and serious } \\
\text { AEs }\end{array}$ \\
\hline
\end{tabular}

AAER: Annualized asthma exacerbation rate; AE: Adverse event; ICS: Inhaled corticosteroid; LABA: Long-acting $\beta_{2}$ agonist; LTS: Long-term study; OCS: Oral corticosteroid; Q2W: Every 2 weeks; Q4W: Every 4 weeks; SC: Subcutaneous.

outcomes following tralokinumab treatment. Identification of a subgroup of participants with severe asthma who had evidence of IL-13 axis activation and subsequent confirmation of an enhanced benefit in this population with tralokinumab would be an important step forward in developing a personalized approach to severe asthma care.

\section{Primary objectives}

The tralokinumab Phase III clinical program was designed to address two fundamental questions: Does tralokinumab provide benefit in severe asthma?; is there a subgroup of the severe asthma population that derives enhanced benefit from tralokinumab? A novel approach was taken to address these questions. Two pivotal Phase III studies, STRATOS 1 and STRATOS 2, both of which included similar populations of participants with severe asthma inadequately controlled despite the use of ICS/LABA, were planned with staggered start and end dates. As a primary objective, STRATOS 1 was intended to examine the effect of tralokinumab on the AAER in the all-comers population and an exploratory objective was to identify a subgroup of participants with an enhanced benefit profile. In addition, STRATOS 1 aimed to assess the safety and tolerability of tralokinumab. The aim of STRATOS 2 was to validate the findings of enhanced benefit (and safety) in the identified subgroup. Staggering of the end dates for these studies allowed analysis of STRATOS 1 and appropriate revision of the STRATOS 2 statistical analysis plan. Linking the two studies was an exploratory biomarker analysis plan that would assess the value of multiple biomarkers in predicting tralokinumab benefit and identify the most appropriate threshold for determining a biomarker-positive subgroup. The two trials did not meet their primary objectives, and the results will be presented in full in a future publication.

\section{Study design \& treatment}

STRATOS 1 and STRATOS 2 were both Phase III, randomized, double-blind, parallel-group, multicenter, placebocontrolled trials. The trials were conducted concurrently, but with staggered start and end dates to allow sequential analysis, as outlined above and described further below. The key inclusion and exclusion criteria for both studies are summarized in Table 2. In STRATOS 1, 1207 participants were randomized at 198 sites, while in STRATOS 2, 856 participants were randomized at 170 sites. The studies consisted of a 4-6-week run-in period, a 52-week treatment period and follow-up visits at weeks 56 and 72. In STRATOS 1, participants received $300 \mathrm{mg}$ tralokinumab or placebo SC Q2W (total 26 doses), or $300 \mathrm{mg}$ tralokinumab or placebo SC every 4 weeks (Q4W) (total 13 doses) (each in a 2:1 ratio), while in STRATOS 2, participants received $300 \mathrm{mg}$ tralokinumab or placebo SC Q2W (total 26 doses) in a 1:1 ratio. At randomization, participants were stratified by baseline serum periostin concentration 


\begin{tabular}{|c|c|c|c|c|c|}
\hline & STRATOS 1 [27] & STRATOS 2 [27] & TROPOS [28] & MESOS [29] & Japanese LTS \\
\hline \multicolumn{6}{|l|}{ Inclusion criteria } \\
\hline Age (years) & $12-75$ & $12-75$ & $12-75$ & $18-75$ & $12-75$ \\
\hline Weight (kg) & $\geq 40-<150$ at enrollment & $\geq 40-<150$ at enrollment & $\geq 40-<150$ at enrollment & $\geq 40-<150$ at enrollment & $\geq 40-<150$ at enrollment \\
\hline Ethnicity & Any & Any & Any & Any & Japanese \\
\hline History of asthma & $\begin{array}{l}\text { - Physician-diagnosed } \\
\text { asthma for } \geq 12 \text { months } \\
\text { before enrollment } \\
\text { - } \geq 2 \text { exacerbations in } \\
12 \text { months prior to } \\
\text { enrollment requiring SCS }\end{array}$ & $\begin{array}{l}\text { - Physician-diagnosed } \\
\text { asthma for } \geq 12 \text { months } \\
\text { before enrollment. } \\
\bullet \geq 2 \text { exacerbations in } \\
12 \text { months prior to } \\
\text { enrollment requiring SCS }\end{array}$ & $\begin{array}{l}\text { - Physician-diagnosed } \\
\text { asthma for } \geq 12 \text { months } \\
\text { before enrollment }\end{array}$ & $\begin{array}{l}\text { - Physician-diagnosed } \\
\text { asthma for } \geq 12 \text { months } \\
\text { before enrollment }\end{array}$ & $\begin{array}{l}\text { - Physician-diagnosed } \\
\text { asthma for } \geq 12 \text { months } \\
\text { before enrollment. } \\
\bullet \geq 1 \text { exacerbations in } \\
12 \text { months prior to } \\
\text { enrollment requiring SCS }\end{array}$ \\
\hline Lung function & $\begin{array}{l}\text { - Pre-BD FEV } 1<80 \% \\
\text { predicted ( }<90 \% \text { in } \\
\text { adolescents) at } \\
\text { enrollment } \\
\text { - Post-BD FEV } \\
\text { reversibility of } \geq 12 \% \text { and } \\
\geq 200 \mathrm{ml} \text { at run-in }\end{array}$ & $\begin{array}{l}\text { - Pre-BD FEV } 1<80 \% \\
\text { predicted ( }<90 \% \text { in } \\
\text { adolescents) at } \\
\text { enrollment } \\
\text { - Post-BD FEV } 1 \\
\text { reversibility of } \geq 12 \% \text { and } \\
\geq 200 \mathrm{ml} \text { at run-in }\end{array}$ & $\begin{array}{l}\text { - Pre-BD FEV } 1<80 \% \\
\text { predicted ( }<90 \% \text { in } \\
\text { adolescents) at } \\
\text { enrollment } \\
\text { - Post-BD FEV } 1 \\
\text { reversibility of } \geq 12 \% \text { at } \\
\text { enrollment or } \\
\text { documented reversibility } \\
\text { within } 6 \text { months before } \\
\text { enrollment }\end{array}$ & $\begin{array}{l}\text { - Pre-BD FEV } 1>50 \% \text { and } \\
>1 \text { I at enrollment } \\
\text { - Post-BD FEV } \\
\text { reversibility of } \geq 12 \% \text { and } \\
\geq 200 \mathrm{ml} \text { at run-in }\end{array}$ & $\begin{array}{l}\text { - Pre-BD } \geq 40 \% \text { predicted at } \\
\text { enrollment or run-in }\end{array}$ \\
\hline Asthma control & $\begin{array}{l}\text { ACQ- } 6 \text { score } \geq 1.5 \text { at } \\
\text { enrollment or run-in }\end{array}$ & $\begin{array}{l}\text { ACQ-6 score } \geq 1.5 \text { at } \\
\text { enrollment or run-in }\end{array}$ & $\mathrm{N} / \mathrm{A}$ & $\begin{array}{l}\text { ACQ-6 score } \geq 1.5 \text { at } \\
\text { enrollment or run-in }\end{array}$ & $\begin{array}{l}\text { ACQ-6 score } \geq 1.5 \text { at } \\
\text { enrollment or run-in }\end{array}$ \\
\hline Current asthma treatment & $\begin{array}{l}\text { - Medium- to } \\
\text { high-dosage ICS for } \\
\geq 6 \text { months of } 12 \text { months } \\
\text { before enrollment } \\
\text { - Documented ICS (total } \\
\text { daily dose } \geq 500 \mu \mathrm{g} \\
\text { fluticasone propionate } \\
\text { DPI or equivalent)/LABA } \\
\text { for } \geq 3 \text { months prior to } \\
\text { enrollment }\end{array}$ & $\begin{array}{l}\text { - Medium- to } \\
\text { high-dosage ICS for } \\
\geq 6 \text { months of } 12 \text { months } \\
\text { before enrollment } \\
\text { - Documented ICS (total } \\
\text { daily dose } \geq 500 \mu \mathrm{g} \\
\text { fluticasone propionate } \\
\text { DPI or equivalent)/LABA } \\
\text { for } \geq 3 \text { months prior to } \\
\text { enrollment }\end{array}$ & $\begin{array}{l}\text { - Medium- to } \\
\text { high-dosage ICS for } \\
\geq 6 \text { months of } 12 \text { months } \\
\text { before enrollment } \\
\text { - Documented ICS (total } \\
\text { daily dose } \geq 500 \mu \mathrm{g} \\
\text { fluticasone propionate } \\
\text { DPI or equivalent)/LABA } \\
\text { for } \geq 3 \text { months prior to } \\
\text { enrollment } \\
\text { - OCS for } 6 \text { months } \\
\text { before visit } 1 \text { and stable } \\
\text { OCS dose } \geq 7.5-\leq 30 \mathrm{mg} \\
\text { (prednisone or } \\
\text { equivalent) daily for } \\
\geq 1 \text { month before } \\
\text { enrollment }\end{array}$ & $\begin{array}{l}\text { - ICS ( } \geq 250 \mu \mathrm{g} \\
\text { fluticasone propionate } \\
\text { DPI or equivalent) alone } \\
\text { or in combination for } \\
\geq 6 \text { months, with stable } \\
\text { dose for } \geq 1 \text { month prior } \\
\text { to enrollment }\end{array}$ & $\begin{array}{l}\text { - Medium- to high-dosage } \\
\text { ICS for } \geq 6 \text { months of } \\
12 \text { months before } \\
\text { enrollment } \\
\text { - Documented ICS (total } \\
\text { daily dose } \geq 500 \mu \mathrm{g} \\
\text { fluticasone propionate DPI } \\
\text { or equivalent; }>200 \mu \mathrm{g} \text { for } \\
\text { patients } \leq 15 \text { years } \\
\text { old) } / \text { LABA for } \geq 3 \text { months } \\
\text { prior to enrollment }\end{array}$ \\
\hline
\end{tabular}

\begin{tabular}{|c|c|c|c|c|c|}
\hline \multicolumn{6}{|l|}{ Exclusion criteria } \\
\hline Comorbidities & $\begin{array}{l}\text { - Clinically important } \\
\text { pulmonary disease other } \\
\text { than asthma } \\
\text { - History of anaphylaxis } \\
\text { following any biologic } \\
\text { treatment }\end{array}$ & $\begin{array}{l}\text { - Clinically important } \\
\text { pulmonary disease other } \\
\text { than asthma } \\
\text { - History of anaphylaxis } \\
\text { following any biologic } \\
\text { treatment }\end{array}$ & $\begin{array}{l}\text { - Clinically important } \\
\text { pulmonary disease, other } \\
\text { than asthma; associated } \\
\text { with increased peripheral } \\
\text { eosinophil counts }\end{array}$ & $\begin{array}{l}\text { - History of interstitial } \\
\text { lung disease, chronic } \\
\text { obstructive pulmonary } \\
\text { disease or other clinically } \\
\text { significant lung disease } \\
\text { other than asthma }\end{array}$ & $\begin{array}{l}\text { - Clinically important } \\
\text { pulmonary disease other } \\
\text { than asthma } \\
\text { - History of anaphylaxis } \\
\text { following any biologic } \\
\text { treatment }\end{array}$ \\
\hline Exacerbation history & $\begin{array}{l}\text { Clinically significant } \\
\text { exacerbations, including } \\
\text { those which require use } \\
\text { of OCS } 30 \text { days prior to } \\
\text { enrollment, or during the } \\
\text { screening/run-in period }\end{array}$ & $\begin{array}{l}\text { Clinically significant } \\
\text { exacerbations, including } \\
\text { those which require use } \\
\text { of OCS } 30 \text { days prior to } \\
\text { enrollment, or during the } \\
\text { screening/run-in period }\end{array}$ & $\begin{array}{l}\text { Clinically significant } \\
\text { asthma exacerbations } \\
\leq 30 \text { days prior to } \\
\text { informed consent or } \\
\text { during run-in period }\end{array}$ & $\begin{array}{l}\text { Hospitalization or OCS } \\
\text { requirement within } 6 \\
\text { weeks of enrollment; or } \\
\text { history of }>3 \\
\text { exacerbations requiring } \\
\text { corticosteroid treatment } \\
\text { in the previous year; or } \\
\text { history of intubation/ICU } \\
\text { in the previous year }\end{array}$ & $\begin{array}{l}\text { Clinically significant } \\
\text { exacerbations, including } \\
\text { those which require use of } \\
\text { OCS } 30 \text { days prior to } \\
\text { enrollment, or during the } \\
\text { screening/run-in period }\end{array}$ \\
\hline OCS use & $\begin{array}{l}\text { OCS use within } 3 \text { months } \\
\text { prior to enrollment }\end{array}$ & $\begin{array}{l}\text { OCS use within } 3 \text { months } \\
\text { prior to enrollment }\end{array}$ & $\mathrm{N} / \mathrm{A}$ & $\begin{array}{l}\text { Long-term OCS use. } \\
\text { OCS use within } 6 \text { weeks } \\
\text { of enrollment }\end{array}$ & $\begin{array}{l}\text { OCS use within } 3 \text { months } \\
\text { prior to enrollment }\end{array}$ \\
\hline Asthma control & $\mathrm{N} / \mathrm{A}$ & $\mathrm{N} / \mathrm{A}$ & $\begin{array}{l}\text { Asthma control reached } \\
\text { at OCS dose } \leq 5 \mathrm{mg} \\
\text { during run-in or OCS } \\
\text { optimization period }\end{array}$ & $\mathrm{N} / \mathrm{A}$ & $\mathrm{N} / \mathrm{A}$ \\
\hline
\end{tabular}


$(<16.44 \mathrm{ng} / \mathrm{ml}$ or $\geq 16.44 \mathrm{ng} / \mathrm{ml}$ ), geographical region and age group (adult or adolescent). Written informed consent was obtained from all participants prior to the start of the study; for participants below the age of majority (as per local law), consent was also obtained from a legal guardian.

\section{Outcome measures}

The primary outcome measure of both STRATOS 1 and STRATOS 2 was the AAER up to week 52. An asthma exacerbation was defined by worsening of asthma requiring use of systemic corticosteroids for $\geq 3$ days, an emergency room or urgent care visit because of asthma (which required systemic corticosteroids), or an inpatient hospitalization because of asthma. Key secondary outcome measures for both trials included: change from baseline in $\mathrm{FEV}_{1}$; daily asthma symptom score; Asthma Quality of Life Questionnaire score; and Asthma Control Questionnaire (ACQ6) score. In addition to periostin and DPP-4, fractional exhaled nitric oxide (FeNO), blood eosinophils and total serum IgE were assessed as potential predictive biomarkers for increased IL-13 activation (STRATOS 1). Safety, tolerability, immunogenicity and PK were also assessed. Further details on outcome measures are found in Panettieri et al. [27].

\section{Statistical methodology}

In both studies efficacy and patient-reported outcome (PRO) analyses were assessed using the full analysis set (FAS; all randomized participants who received any investigational product) and were categorized by randomized treatment group. The safety analysis sets included all participants who received any investigational product, categorized by treatment received and were used for all safety and immunogenicity evaluations. Planned sample sizes of 1140 participants (380 per tralokinumab treatment arm, 190 per placebo treatment arm) for STRATOS 1, and 770 participants (385 per treatment arm) for STRATOS 2 were considered sufficient to demonstrate reductions in the AAER with tralokinumab compared with placebo. Further details on the sample size calculation are provided in Panettieri et al. [27].

In both studies, the AAER was assessed using a negative binomial model. In STRATOS 2, for the analysis of the biomarker subgroups only, a variable for the biomarker subgroup (positive, negative), and a treatmentby-biomarker subgroup interaction term were included in the model. Key secondary outcome measures were assessed using repeated measures analysis. Full details on the analysis of the outcome measures can be found in Panettieri et al. [27].

Multiple testing procedures in each study were prespecified to strongly control the Type I error across primary and key secondary end points $\left(\mathrm{FEV}_{1}\right.$, Asthma Quality of Life Questionnaire, ACQ-6 and mean daily asthma symptom score). In STRATOS 1, end points were formally tested in the all-comers population, while in STRATOS 2 , end points were formally tested first in the biomarker-positive subgroup as identified in STRATOS 1, and then in the all-comers population. Further details on the testing strategy are provided in Figure 2.

\section{The TROPOS study}

Rationale for study

STRATOS 1 and STRATOS 2 did not include the entire spectrum of severe asthma, as participants receiving OCS at study entry were excluded from these trials. As described above, overuse of OCS has detrimental effects on health-related quality of life and alternative, effective treatments are required. TROPOS addressed this need by using an end point relevant for this OCS-dependent participant population, reduction of OCS dosage, rather than AAER as used in STRATOS 1 and 2.

\section{Primary objective}

The primary objective of TROPOS was to assess the effect of tralokinumab in reducing the OCS dosage in an unselected population of participants with asthma who require treatment with maintenance OCS in addition to ICS plus LABA. This primary objective was not met, and the full data from TROPOS will be published in full in the near future.

\section{Study design \& treatment}

TROPOS was a Phase III, randomized, double-blind, parallel-group, multicenter, placebo-controlled study; 140 participants were randomized at 44 sites. The key inclusion and exclusion criteria are summarized in Table 2 . The study included a 2-week run-in period or a 2-week run-in period plus an 8-week optimization period (if there had 
(A)

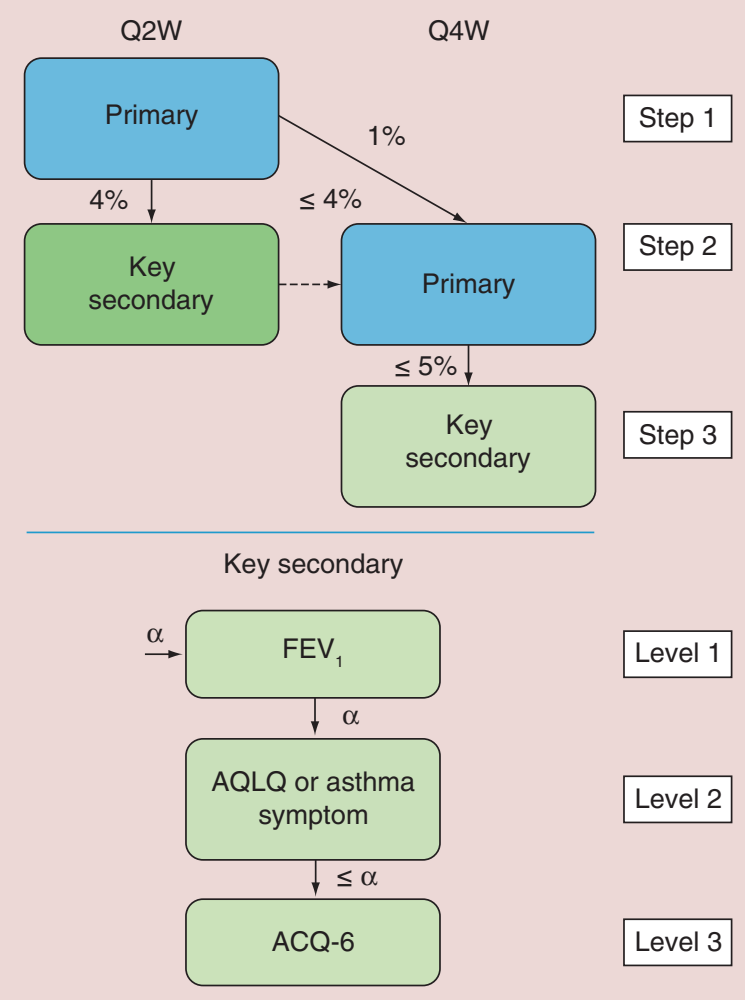

(B)

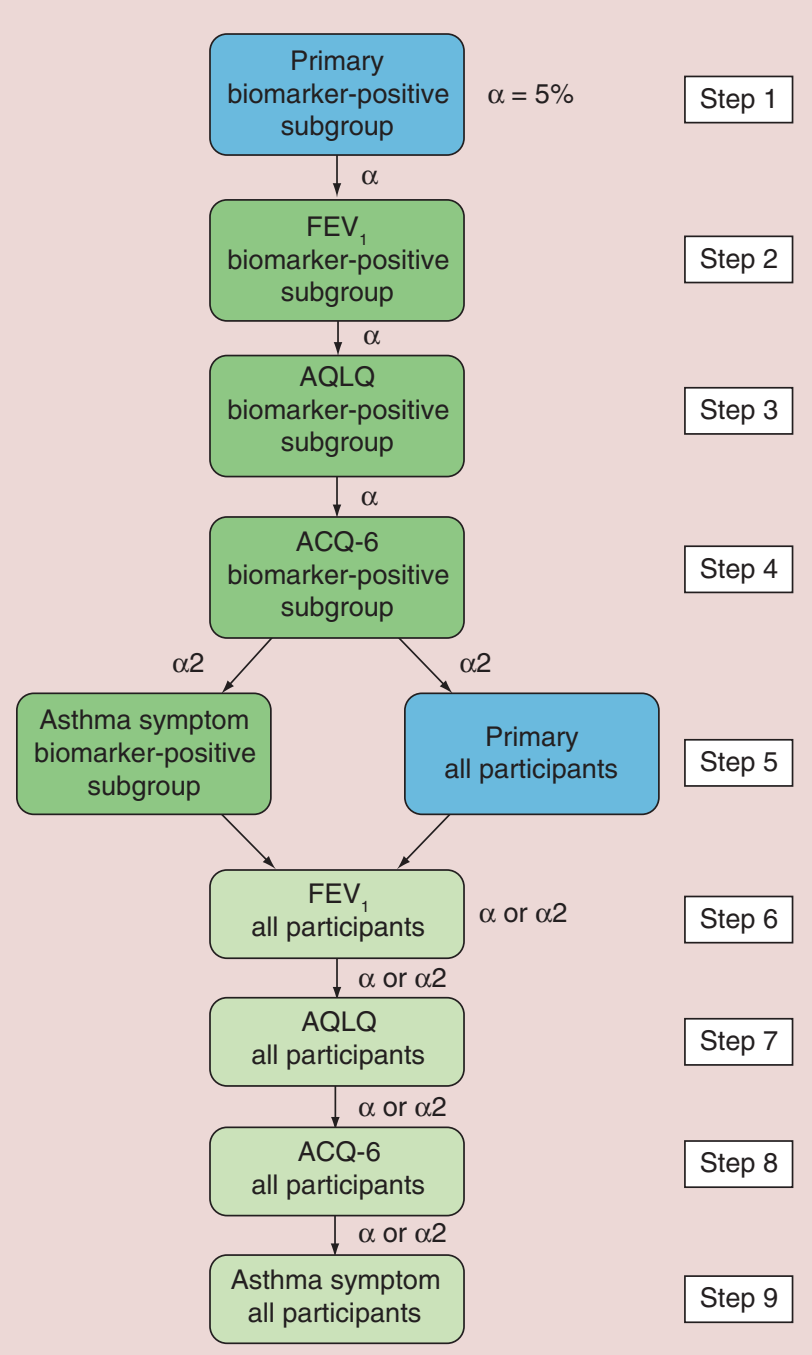

Figure 2. Testing strategy for primary and key secondary outcomes in STRATOS 1 and STRATOS 2.

A predefined hierarchical testing strategy for the primary and key secondary outcome measures was applied to provide strong global control of type I errors (family-wise error rate). A significant effect was required at each step in order to move on to the following step, otherwise testing would be stopped and all subsequent results would be considered nonsignificant.

(A) STRATOS 1

- Step 1: tralokinumab $300 \mathrm{mg}$ SC Q2W was assessed versus placebo with regard to the AAER (two-sided significance level [ $\alpha$ ] of 0.05 ).

- Step 2: the effect of tralokinumab on the key secondary outcome measures was tested (two-sided $\alpha$ of 0.04 ), using the hierarchical strategy shown. The AAER was then tested for tralokinumab $300 \mathrm{mg}$ SC Q4W (two-sided $\alpha$ of $\geq 0.01$ ); the $\alpha$ used was determined by the results of the tests on the key secondary end points.

- Step 3: if treatment effect was demonstrated for tralokinumab Q4W in step 2, the key secondary outcome measures were tested for tralokinumab Q4W ( $\alpha$ retained from step 2).

(B) STRATOS 2

In STRATOS 2, end points were assessed first in the biomarker-positive subgroup as identified in STRATOS 1 (steps 1-5), and then the all-comers population (steps 5-9).

- Step 1: the AAER was tested (two-sided $\alpha$ of 0.05 ) in the biomarker-positive subgroup.

- Steps 2-4: FEV 1 , AQLQ and ACQ-6 were then tested sequentially in the same population (two-sided $\alpha$ of 0.05 ).

- Step 5: if a significant treatment effect was demonstrated for ACQ-6 in the biomarker-positive subgroup, then mean daily asthma symptom score in the biomarker-positive subgroup and AAER in the all-comers population were both tested using a Bonferroni approach at $\alpha / 2$ of 0.025 . If a significant effect was observed for at least one end point in this step, testing proceeded to step 6.

- Step 6: $\mathrm{FEV}_{1}$ was tested in the all-comers population; the significance level used depended on whether only one (resulting in $\alpha / 2$ of 0.025 ) or both (resulting in $\alpha$ of 0.05 ) outcome measures were found to be significant at step 5 .

- Steps 7-9: The effects on AQLQ, ACQ-6 and mean daily symptom score in the all-comers population were successively tested using $\alpha$ retained from step 6.

AAER: Annualized asthma exacerbation rate; ACQ-6: Asthma Control Questionnaire; AQLQ: Asthma Quality of Life Questionnaire; FEV : $^{2}$ Forced expiratory volume in $1 \mathrm{~s}$; Q2W: Every 2 weeks; Q4W: Every 4 weeks; SC: Subcutaneous. 
not been a failure of OCS dosage reduction in the past 6 months prior to visit 1), to establish a minimum effective dosage of the prescribed OCS. The 40-week treatment period consisted of three phases: the induction phase (12 weeks), when participants remained on their optimized dosage of OCS (weeks 0-12); the OCS reduction phase (20 weeks), when OCS dosage was reduced at 4-week intervals (weeks 12-32); and the maintenance phase (8 weeks), when participants remained on the OCS dosage (could be $0 \mathrm{mg}$ ) reached at week 32 during the reduction phase. Follow-up visits took place at weeks 44 and 54. Participants received $300 \mathrm{mg}$ tralokinumab or placebo SC Q2W (total 20 doses) and were stratified by age group and OCS dosage ( $\leq 10 \mathrm{mg}$ vs $>10 \mathrm{mg}$ prednisone/prednisolone; adult participants) at randomization. Written informed consent was obtained from all participants prior to the start of the study; for participants below the age of majority (as per local law), consent was also obtained from a legal guardian.

\section{Outcome measures}

The primary outcome measure of TROPOS was the percentage change from baseline in the average OCS dosage at week 40, without loss of asthma control in the all-comers population. Secondary outcome measures included the proportion of participants with a prescribed OCS maintenance dosage $\leq 5 \mathrm{mg}$ at the end of the treatment period (week 40), the proportion of participants with $\geq 50 \%$ reduction in their prescribed OCS maintenance dosage at the end of the treatment period (week 40) and the AAER up to week 40 with tralokinumab compared with placebo. The effects of tralokinumab on OCS dosage reduction have also been assessed in a biomarker-positive population, as defined in STRATOS 1. Further details on outcome measures are found in Busse et al. [28].

\section{Statistical methodology}

The analysis sets for TROPOS were as described for STRATOS 1 and STRATOS 2. The original sample size calculation for TROPOS assumed that the targeted difference in the percentage reduction in OCS dosage between tralokinumab and placebo would be $50 \%$ in the all-comers population, which would require at least 55 participants in each treatment group (see Busse et al. [28] for further details). However, following analysis of results from STRATOS 1, which indicated that benefits of tralokinumab on the AAER were restricted to a subgroup of participants with high biomarker concentrations, the statistical analysis methodology for TROPOS was revised to allow the possibility of a primary analysis in a biomarker-high subgroup. In this study with a small sample size and an unknown distribution of baseline biomarker concentrations in a severe asthma population using OCS, two thresholds for a biomarker population were chosen (biomarker-mid and biomarker-high). If the proportion of patients above either threshold was not $\geq 50 \%$, then the primary population would be the all-comers population. Further details on the testing strategy are provided in Figure 3.

The primary efficacy outcome measure, change from baseline in average OCS dosage to week 40, was assessed using an analysis of covariance model with a sandwich estimator for the covariance. Secondary outcome measures were assessed using logistic regression, controlling for OCS dosage at baseline.

\section{The MESOS study \\ Rationale for study}

In previous studies, treatment with tralokinumab increased blood eosinophil numbers [23,24]. This effect is consistent with findings with other biologics that target IL-13 signaling, namely lebrikizumab and dupilumab [30,31]. As blood eosinophils are associated with worse disease outcomes in asthma [32], there is a need to understand whether the increase in blood eosinophils following tralokinumab treatment is associated with a corresponding increase in airway eosinophils. A mathematical modeling analysis of eosinophil dynamics following treatment with anticytokine biologics predicted that, despite an increase in blood eosinophils with tralokinumab treatment, there would be a decrease in lung eosinophils due to decreased release of eosinophil chemotactic factors in the lung [33]. These data were the basis for the hypothesis to be tested in the MESOS study that tralokinumab reduces 'trafficking' of eosinophils from the blood to the lungs, with a consequent increased number in the blood and also a reduction in the number of activated eosinophils [33]. Another hypothesis tested in MESOS was that tralokinumab, as a biologic entering the lungs via the bloodstream, is more likely to improve small airway function than an inhaled drug, which would access the large airways relatively easily, but the small airways less so. 
(A)

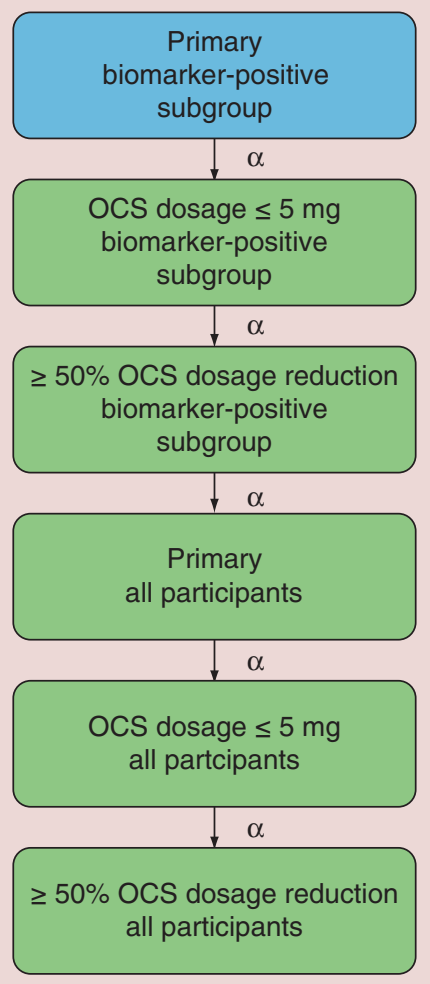

(B)

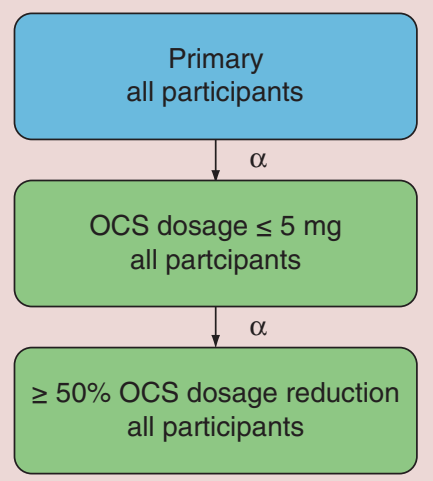

Figure 3. Testing strategy for primary and key secondary outcomes in TROPOS.

Following analysis of STRATOS 1 results, the statistical analysis plan for TROPOS was revised. As TROPOS was fully recruited $(\mathrm{N}=140)$ and the distribution of biomarker concentrations at baseline was not known, the primary population for analysis of the study would instead be determined by the observed distribution of biomarker concentrations. Three cut-off scenarios were devised in order to ensure there were sufficient numbers of patients in each treatment arm for the primary statistical analyses.

(A) Primary population: biomarker-positive subgroup.

- If $\geq 50 \%$ of patients in TROPOS (i.e., $\geq 70$ patients) had baseline biomarker concentrations above the cut-offs identified in STRATOS 1 (i.e., biomarker-high), this biomarker-defined population would become the primary population for testing the primary and secondary outcome measures.

- In this study with a small sample size and an unknown distribution of baseline biomarker concentrations in a severe asthma population using OCS, a second lower, but still clinically meaningful, threshold for the biomarker-high population was also chosen. If $<50 \%$ of patients had biomarker concentrations above the threshold defined in STRATOS 1 , but $\geq 50 \%$ of patients had biomarker concentrations above the second, lower, cut-off, the primary population could comprise all patients with biomarker concentrations above this alternative cut-off (i.e., a biomarker-mid and biomarker-high subgroup).

- As per the original plan, it was expected that the treatment effect would be $50 \%$ OCS reduction in the biomarker-high subgroup, $30 \%$ OCS reduction in the biomarker-mid subgroup and $0 \%$ OCS reduction in the biomarker-low subgroup.

- The standard deviation of OCS reduction responses would be $80 \%$, and the two-sided type I error rate would be $5 \%$. - If biomarker-high was the primary population (minimum $50 \%$ prevalence), $\geq 35$ patients per arm would provide $\geq 73 \%$ power. If biomarker-mid and -high was the primary population (minimum $50 \%$ prevalence), the power would be $34-83 \%$.

(B) Primary population: all-comers population.

- If $\geq 50 \%$ of the patients had biomarker concentrations below either of the two thresholds described above

(i.e., biomarker-low), the primary population would be the all-comers population.

- If the all-comers population was the primary population, 70 patients per arm would provide $2.5-44 \%$ power.

OCS: Oral corticosteroid. 


\section{Primary objective}

The primary objective of MESOS was to assess the effect of tralokinumab on eosinophilic airway inflammation and airway remodeling in participants with asthma that remains inadequately controlled despite the use of ICS.

Study design \& treatment

This was a Phase II, randomized, double-blind, parallel-group, multicenter, placebo-controlled trial, with 79 participants randomized at 14 sites. The key inclusion and exclusion criteria are summarized in Table 2; in addition to these criteria, participants were required to have a successful bronchial biopsy procedure, as judged by the investigator. The study consisted of a 12-week treatment period and a 14-week follow-up period, with participants receiving $300 \mathrm{mg}$ tralokinumab or placebo SC Q2W for a total of six doses. Written informed consent was obtained from all participants prior to the start of the study.

\section{Outcome measures}

The primary outcome measure was the change in number of airway submucosal eosinophils per $\mathrm{mm}^{2}$ from baseline to week 12 in bronchoscopic biopsies following tralokinumab treatment compared with placebo. Secondary outcome measures included: change from baseline to week 12 in number of blood eosinophils; number of differential sputum eosinophils; and blood- and sputum-free ECP concentrations with tralokinumab versus placebo. Exploratory outcome measures included small and large airway structure and function. Further details on outcome measures are found in Brightling et al. [29].

\section{Statistical methodology}

The all-subjects analysis set included all participants screened for the study (disposition and screening failures data); the FAS included all participants who were randomized and received investigational product, regardless of their protocol adherence and continued participation in the study (efficacy data); the safety analysis set included all participants who received investigational product (safety data); the PK analysis set included all participants in the FAS who received investigational product, with the assumption that PK blood samples were not affected by protocol deviations; and the PRO analysis set was defined based on the FAS (PRO data). The sample size was based on the primary outcome measure, change from baseline to week 12 in airway submucosal eosinophils. Based on the assumed standard deviation of the log values in the two treatment groups being 1.62 (tralokinumab) and 1.82 (placebo), it was estimated that 31 participants in each treatment arm would be sufficient to achieve $\geq 80 \%$ power to detect a 3.5-fold difference versus placebo using a two-sided test at $5 \%$ significance level.

The primary outcome measure was assessed using an analysis of covariance with at least baseline value and treatment as covariates, while secondary outcome measures were assessed using a mixed model for repeated measures with at least treatment as covariate.

\section{Japanese long-term study}

Rationale for study

A population PK modeling analysis of tralokinumab in Japanese healthy volunteers and people with asthma demonstrated that dose adjustment for individuals of Japanese ethnicity would not be required. Further to this, Japanese participants in the ATMOSPHERE program received the $300 \mathrm{mg}$ Q2W SC dosage selected through the $\mathrm{PK} /$ pharmacodynamic modeling analysis of the Phase II studies, which included both Japanese and non-Japanese participants [25]. This long-term study aimed to provide additional safety and efficacy data for this dosage of tralokinumab in Japanese participants.

\section{Primary objective}

The objective of this study was to assess the long-term safety and tolerability of tralokinumab in Japanese people with asthma inadequately controlled despite the use of ICS/LABA.

\section{Study design \& treatment}

This was a Phase III, open-label study in which 28 Japanese participants received treatment (300 mg tralokinumab SC Q2W; total of 26 doses) at four sites in Japan. The key inclusion and exclusion criteria are summarized in Table 2. The study consisted of a run-in period of maximum 2 weeks, a 52-week treatment period and follow-up 
visits at weeks 56 and 66. Written, informed consent was obtained from all participants prior to the start of the study; for participants $<20$ years of age, consent was also obtained from a legal guardian.

\section{Outcome measures}

Primary outcome measures included the number of AEs and serious AEs, laboratory variables, vital signs, electrocardiograms and physical examinations. Exploratory outcome measures included: ACQ-6 score; percentage change from baseline in $\mathrm{FEV}_{1}$; AAER (an exacerbation was defined as a worsening of asthma requiring systemic corticosteroids for $\geq 3$ days, an emergency room visit, or inpatient hospitalization); baseline concentrations and change from baseline in biomarkers (periostin, DPP-4 and others that might be associated with upregulation of IL-13); serum tralokinumab concentration; and incidence of antidrug antibodies and characterization of their neutralizing potential.

\section{Statistical methodology}

The safety and immunogenicity assessments were based on the safety analysis set, which included all participants who received at least one dose of tralokinumab. The FAS included all participants receiving any dose of tralokinumab, regardless of protocol adherence or continued participation, and was used for the exploratory efficacy and PRO analyses. The PK analysis set, used for PK assessments, comprised all participants from the FAS, excluding those whose PK blood samples may be affected by protocol deviations (e.g., taking disallowed medications). No formal sample size calculation was performed, given the objectives of the study. Approximately 22 Japanese participants (who completed the planned 52-week treatment period) were considered sufficient for collecting additional safety information on tralokinumab. Descriptive statistics were used for all outcome measures.

\section{Potential biomarkers in IL-13-driven asthma}

A biomarker can be defined as "any substance, structure or process that can be measured in the body or its products, and influence or predict the incidence of outcome or disease" [34]. Ideally, biomarkers should be easy to collect and measure noninvasively and relatively inexpensively [35]. Five potential biomarkers for IL-13 activity have been identified, including proteins derived from the bronchial epithelium (e.g., DPP-4 and periostin), FeNO, blood eosinophils and total serum IgE (Figure 4). The utilization of these five biomarkers in the STRATOS 1 and STRATOS 2 studies to identify a subgroup of participants with severe asthma who would obtain enhanced benefit from tralokinumab is a step forward in enabling a personalized approach to the treatment of IL-13-driven asthma.

\section{Dipeptidyl peptidase-4}

DPP-4 is multifunctional protein expressed in bronchial epithelial cells and its expression is increased in response to IL-13 [36]. The role of DPP-4 in the pathophysiology of asthma is not established, but it might be involved in airway inflammation, cell proliferation and fibronectin production. Specifically, DPP-4 increases the proliferation of lung fibroblasts and bronchial smooth muscle cells, as well as production of fibronectin from these cells. It is also involved in T-cell activation [37]. As a biomarker, DPP-4 can be measured in the blood using a validated immunoassay [38]. In a Phase IIb study, a subset of participants with elevated serum DPP-4 concentrations, baseline $\mathrm{FEV}_{1}$ reversibility, no long-term OCS and who received tralokinumab, achieved improvements in lung function, asthma control and quality of life compared with those participants who had low concentrations of DPP-4 [24].

\section{Periostin}

Periostin is a matricellular protein expressed in airway fibroblasts and epithelial cells, and its expression is increased in response to IL-4, IL-13 or TGF- $\beta$ [39]. Periostin promotes eosinophil adhesion and recruitment to the airways, which could contribute to increased airway type- 2 inflammation and fibrosis in the lungs of participants with asthma [40,41]. It also activates eosinophil-specific functions: $\mathrm{O}_{2}{ }^{-}$generation and eosinophil-derived neurotoxin release [42]. Similarly to DPP-4, periostin is a noninvasive biomarker that can be measured in the blood using a validated immunoassay [43]. In a Phase IIb study, a subset of participants with elevated serum periostin concentrations, baseline $\mathrm{FEV}_{1}$ reversibility, no long-term OCS and who received tralokinumab, achieved improvements in the AAER, lung function and asthma control (ACQ-6) compared with those with low concentrations of periostin [24]. 


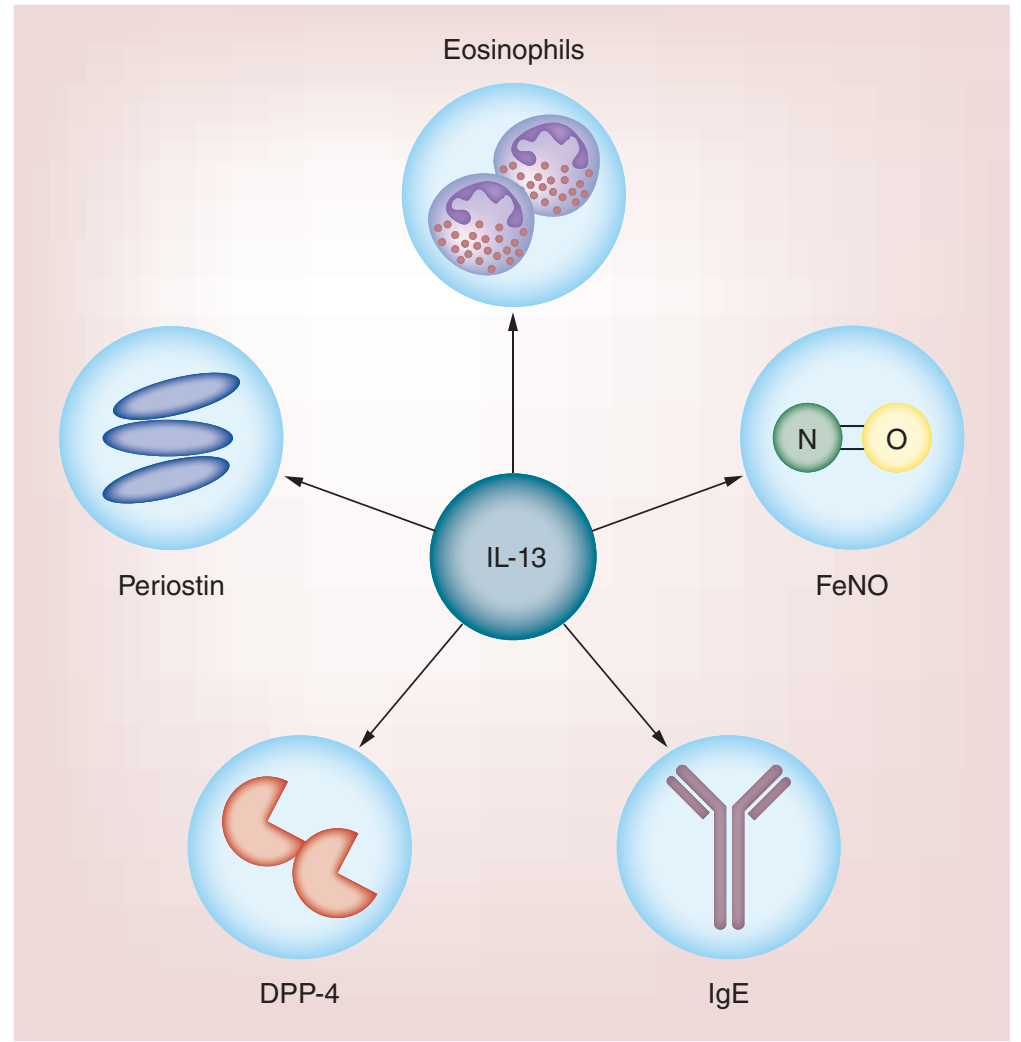

Figure 4. Potential biomarkers of IL-13-driven asthma. FeNO: Fractional exhaled nitric oxide.

\section{Fractional exhaled nitric oxide}

The role of NO in the airways is complex [44]. It might function as a proinflammatory mediator contributing to airway hyper-responsiveness, while under physiological conditions it contributes to smooth muscle relaxation and inhibits airway hyper-responsiveness [45,46]. FeNO is the concentration of $\mathrm{NO}$ in exhaled breath and can be measured using a variety of techniques and devices; however, the sensitivity and accuracy of these devices can vary, limiting repeatability [47]. High FeNO concentrations can indicate elevated type-2 inflammation [48], which is often seen in asthma, and is associated with an increased risk of exacerbations [47]. In addition, there is an association between FeNO and steroid insensitivity in some participants with asthma [49]. FeNO has been measured as a biomarker of type- 2 inflammation in several past and ongoing clinical trials of biologics in severe asthma $[27,31,50,51]$. It is specifically linked to IL-13 axis activation through the activity of inducible NO synthase (iNOS), an enzyme responsible for producing NO in the airways [52] that is upregulated by IL-13 [53]. The results of STRATOS 1 and STRATOS 2 will therefore help to understand the potential benefit of this biomarker for guiding personalized treatment in IL-13-driven disease.

\section{Eosinophils}

Eosinophils are leukocytes that are involved in the innate immune response to external stimuli, including helminth parasites, viruses and allergens [54]. They are recruited to sites of inflammation (such as the lungs) by type2 cytokines [55], where they release proinflammatory cytokines and cytotoxic molecules that contribute to the pathogenesis of asthma [56]. Elevated eosinophil counts in the airway and blood are associated with decreased lung function, increased disease severity and frequent exacerbations [55,57]. Blood eosinophil counts are used as the biomarker to identify participants likely to benefit from anti-IL-5 biologics [58-61]. In participants receiving tralokinumab as part of a Phase IIb study, there were trends toward an AAER reduction and improved lung function in subgroups with high type- 2 status (defined as serum $\mathrm{IgE}>100 \mathrm{IU} / \mathrm{ml}$ and blood eosinophils $\geq 140 \mathrm{cells} / \mu \mathrm{l}$ ) and those with baseline peripheral blood eosinophil counts $\geq 300 \mathrm{cells} / \mu \mathrm{l}[24]$. 
$\operatorname{Ig} E$

IgE is typically involved in host responses to helminth parasites, but also has a central role in the pathophysiology of allergic reactions, including atopic asthma [62]. In the lungs, allergen-specific IgE triggers mast cells and basophils to degranulate upon contact with the allergen, which leads to bronchoconstriction, edema and recruitment of other immune cells to the site of inflammation [62]. Allergen-specific IgE can be used as a biomarker for atopic asthma, and there is an inverse correlation between elevated serum IgE concentrations and reduced lung function [63-65]. IgE has been measured in several clinical trials of biologics in severe asthma [27,31,50,66,67], and serum total IgE is used to determine the dose of omalizumab used in participants with allergic asthma [68]. In a Phase IIb study investigating the efficacy and safety of tralokinumab in participants with severe, uncontrolled asthma, serum IgE was one parameter used to identify participants who were 'type- 2 high' (defined as $\mathrm{IgE}>100 \mathrm{IU} / \mathrm{ml}$ and blood eosinophils $\geq 140 \mathrm{cells} / \mu \mathrm{l}$ ); there was a trend toward AAER reduction and improved lung function in this subgroup [24].

\section{Conclusion \& future perspective}

Asthma, particularly severe asthma, represents a heterogeneous disease that responds differently to treatments, and established therapies have limitations in the management of the disease. A major unmet need remains for people with severe asthma whose disease is inadequately controlled with high-dosage ICS/LABA. In addition, these patients can become reliant on OCS treatment, which is associated with serious AEs. The ATMOSPHERE program was developed to assess whether tralokinumab, an anti-IL-13 monoclonal antibody, has beneficial effects for people with severe, uncontrolled asthma. In the tralokinumab Phase III clinical development program, a novel approach was implemented to address two key objectives, specifically whether tralokinumab would provide benefit in severe asthma and whether there was a subgroup of participants with severe asthma who derived enhanced benefit with tralokinumab. STRATOS 1 was initiated and completed before STRATOS 2, thus enabling an exploratory biomarker analysis of the results from STRATOS 1 to be applied to the analysis of STRATOS 2. This approach permitted evaluation of the utility of potential biomarkers for IL-13 activation to allow for a personalized approach in the treatment of people with IL-13-driven, severe asthma. TROPOS assessed the possibility of reduced reliance on OCS, while a study in Japanese individuals was intended to confirm the long-term safety of tralokinumab in this population. Furthermore, MESOS will contribute to our understanding of the mechanism of action of tralokinumab in airway inflammation and remodeling. There are limitations in the study design of the trials in the ATMOSPHERE program. Specifically, when a biomarker-positive subgroup was identified in STRATOS 1, participant recruitment for STRATOS 2 and TROPOS had been completed. Therefore, it was not possible to modify the study design to enrich for the biomarker-positive subgroup; changes could only be made to the statistical analysis plan. In addition, ideally, the MESOS study should have been performed before the Phase III studies to confirm the mechanism of action of tralokinumab as an anti-inflammatory agent.

The ATMOSPHERE program aimed to determine whether a proportion of participants experience an enhanced response to tralokinumab, thus enabling more efficient management of IL-13-driven asthma compared with currently available therapies. Other biologics developed to target IL-13-driven asthma have had mixed success. In Phase III trials, the anti-IL-13 biologic lebrikizumab did not demonstrate a consistent benefit in participants with severe asthma either in the all-comers population or in a subgroup defined by elevated serum periostin and blood eosinophil concentrations [51]. Dupilumab, a biologic developed to inhibit both IL-4 and -13, however, has demonstrated efficacy in both an all-comers population of participants with severe asthma and in those who had elevated blood eosinophil counts in a Phase IIb trial [31]. The studies with tralokinumab, similar to the lebrikizumab experience, were unable to identify a population of participants with consistent, clinically meaningful treatment benefit.

\section{Supplementary data}

An infographic accompanies this paper at the end of the references section. To download the infographic that accompanies this paper, please visit the journal website at: www.futuremedicine.com/doi/full/10.2217/imt-2017-0191

Financial \& competing interests disclosure

This review was funded by AstraZeneca (Cambridge, UK). RA Panettieri has been a consultant and participated in advisory boards for AstraZeneca, Medlmmune and Novartis; has received research grants from AstraZeneca, Novartis, Theratrophix, Oncoarendi, Amgen, RIFM, Vertex and Bristol-Myers Squibb; and has been a speaker for Boston Scientific, and Teva. M Wang, M Braddock, K Bowen and G Colice are employees of AstraZeneca and own stock with AstraZeneca. The authors have no other relevant affiliations 
Executive summary

Asthma overview

- Asthma is a heterogeneous disease, and currently available therapies for disease management have limitations.

- There is a major unmet need for people with severe asthma whose disease remains inadequately controlled despite high-dosage inhaled corticosteroids/long-acting $\beta 2$ agonists, particularly those who depend on long-term oral corticosteroids.

- People with asthma exhibit different underlying mechanisms of inflammation and so respond differently to treatment.

- Some types of asthma are driven by IL-13 signaling.

Background to tralokinumab

- Tralokinumab is a fully human $\operatorname{lgG}_{4}$ monoclonal antibody, which potently and specifically neutralizes IL-3 by preventing its interaction with IL-13R $\alpha 1$ and IL-13R $\alpha 2$.

- In two Phase II studies, tralokinumab treatment improved the symptoms of asthma in participants with severe, uncontrolled asthma and activation of IL-13.

The ATMOSPHERE program

- The ATMOSPHERE clinical program consisted of five clinical trials: STRATOS 1, STRATOS 2, TROPOS, MESOS and a long-term trial in Japanese individuals.

- The program aimed to evaluate tralokinumab for the treatment of people with severe, uncontrolled asthma.

Potential biomarkers in IL-13-driven asthma

- Five potential biomarkers for type-2 airway inflammation and IL-13 activity (DPP-4, periostin, fractional exhaled nitric oxide, eosinophils and IgE) have been evaluated in the ATMOSPHERE program.

- The biomarkers have been assessed for their ability to identify a subgroup of participants most likely to respond to tralokinumab.

Conclusion \& future perspective

- The ATMOSPHERE program has assessed the efficacy and safety of tralokinumab in people with severe, uncontrolled asthma.

- The aim of the ATMOSPHERE program was the identification of a proportion of participants with biomarker-based evidence of IL-13-driven disease most likely to respond to tralokinumab, to allow for more efficient management compared with currently available therapies; however, the studies were unable to identify such a population.

or financial involvement with any organization or entity with a financial interest in or financial conflict with the subject matter or materials discussed in the manuscript apart from those disclosed.

N Panagiotaki (QXV Comms [Macclesfield, UK], an Ashfield Company, part of UDG Healthcare plc), provided medical writing support funded by AstraZeneca (Cambridge, UK), in accordance with Good Publication Practice (GPP3) guidelines (http://www.is mpp.org/gpp3).

\section{Open access}

This work is licensed under the Attribution-NonCommercial-NoDerivatives 4.0 Unported License. To view a copy of this license, visit http://creativecommons.org/licenses/by-nc-nd/4.0/

\section{References}

Papers of special note have been highlighted as: $\bullet$ of interest; $\bullet \bullet$ of considerable interest

1 Masoli M, Fabian D, Holt S, Beasley R, Global Initiative for Asthma Program. The global burden of asthma: executive summary of the GINA Dissemination Committee Report. Allergy 59(5), 469-478 (2004).

2 Global strategy for asthma management and prevention.

http://ginasthma.org/2017-gina-report-global-strategy-for-asthma-management-and-prevention/

3 Chung KF, Wenzel SE, Brozek JL et al. International ERS/ATS guidelines on definition, evaluation and treatment of severe asthma. Eur. Respir. J. 43(2), 343-373 (2014).

4 Lefebvre P, Duh MS, Lafeuille MH et al. Acute and chronic systemic corticosteroid-related complications in patients with severe asthma. J. Allergy Clin. Immunol. 136(6), 1488-1495 (2015).

5 Manson SC, Brown RE, Cerulli A, Vidaurre CF. The cumulative burden of oral corticosteroid side effects and the economic implications of steroid use. Respir. Med. 103(7), 975-994 (2009). 
6 Prazma CM, Wenzel S, Barnes N, Douglass JA, Hartley BF, Ortega H. Characterisation of an OCS-dependent severe asthma population treated with mepolizumab. Thorax 69(12), 1141-1142 (2014).

7 Wenzel SE. Asthma phenotypes: the evolution from clinical to molecular approaches. Nat. Med. 18(5), 716-725 (2012).

8 Pavord ID, Afzalnia S, Menzies-Gow A, Heaney LG. The current and future role of biomarkers in type 2 cytokine-mediated asthma management. Clin. Exp. Allergy 47(2), 148-160 (2017).

9 Woodruff PG, Modrek B, Choy DF et al. T-helper type 2-driven inflammation defines major subphenotypes of asthma. Am. J. Respir. Crit. Care Med. 180(5), 388-395 (2009).

10 Humbert M, Durham SR, Kimmitt P et al. Elevated expression of messenger ribonucleic acid encoding IL-13 in the bronchial mucosa of atopic and nonatopic subjects with asthma. J. Allergy Clin. Immunol. 99(5), 657-665 (1997).

11 Kotsimbos TC, Ernst P, Hamid QA. Interleukin-13 and interleukin-4 are coexpressed in atopic asthma. Proc. Assoc. Am. Physicians 108(5), 368-373 (1996).

12 Komai-Koma M, Mckay A, Thomson L et al. Immuno-regulatory cytokines in asthma: IL-15 and IL-13 in induced sputum. Clin. Exp. Allergy 31(9), 1441-1448 (2001).

13 Kondo M, Tamaoki J, Takeyama K et al. Elimination of IL-13 reverses established goblet cell metaplasia into ciliated epithelia in airway epithelial cell culture. Allergol. Int. 55(3), 329-336 (2006).

14 Batra V, Musani AI, Hastie AT et al. Bronchoalveolar lavage fluid concentrations of transforming growth factor (TGF)- $\beta 1$, TGF- $\beta 2$, interleukin (IL)- 4 and IL-13 after segmental allergen challenge and their effects on $\alpha$-smooth muscle actin and collagen III synthesis by primary human lung fibroblasts. Clin. Exp. Allergy 34(3), 437-444 (2004).

15 Firszt R, Francisco D, Church TD, Thomas JM, Ingram JL, Kraft M. Interleukin-13 induces collagen type-1 expression through matrix metalloproteinase- 2 and transforming growth factor- $\beta 1$ in airway fibroblasts in asthma. Eur. Respir. J. 43(2), 464-473 (2014).

16 Humbles AA, Lloyd CM, Mcmillan SJ et al. A critical role for eosinophils in allergic airways remodeling. Science 305(5691), 1776-1779 (2004).

17 Chiba Y, Nakazawa S, Todoroki M, Shinozaki K, Sakai H, Misawa M. Interleukin-13 augments bronchial smooth muscle contractility with an up-regulation of RhoA protein. Am. J. Respir. Cell Mol. Biol. 40(2), 159-167 (2009).

18 Punnonen J, Aversa G, Cocks BG et al. Interleukin 13 induces interleukin 4-independent IgG4 and IgE synthesis and CD23 expression by human B cells. Proc. Natl Acad. Sci. USA 90(8), 3730-3734 (1993).

19 May RD, Fung M. Strategies targeting the IL-4/IL-13 axes in disease. Cytokine 75(1), 89-116 (2015).

20 Fichtner-Feigl S, Strober W, Kawakami K, Puri RK, Kitani A. IL-13 signaling through the IL-13 2 receptor is involved in induction of TGF- $\beta 1$ production and fibrosis. Nat. Med. 12(1), 99-106 (2006).

21 May RD, Monk PD, Cohen ES et al. Preclinical development of CAT-354, an IL-13 neutralizing antibody, for the treatment of severe uncontrolled asthma. Br. J. Pharmacol. 166(1), 177-193 (2012).

22 Popovic B, Breed J, Rees DG et al. Structural characterisation reveals mechanism of IL-13 neutralising monoclonal antibody tralokinumab as inhibition of binding to IL-13R $\alpha 1$ and IL-13R $\alpha 2$. J. Mol. Biol. 429 208-219 (2017).

- Describes the mechanism of action of tralokinumab, demonstrating that tralokinumab prevents IL-13 from binding to both IL-13R $\alpha 1$ and IL-13R $\alpha 2$.

23 Piper E, Brightling C, Niven R et al. A Phase II placebo-controlled study of tralokinumab in moderate-to-severe asthma. Eur. Respir. J. 41(2), 330-338 (2013).

-. Reports the results of the Phase IIa study of tralokinumab in participants with moderate-to-severe, uncontrolled asthma, demonstrating that tralokinumab treatment is associated with improved lung function in a subgroup of participants with increased IL-13 sputum concentrations at baseline.

24 Brightling CE, Chanez P, Leigh R et al. Efficacy and safety of tralokinumab in patients with severe uncontrolled asthma: a randomised, double-blind, placebo-controlled, Phase 2b trial. Lancet. Respir. Med. 3(9), 692-701 (2015).

-• Reports the results of the Phase IIb study of tralokinumab in participants with severe, uncontrolled asthma, demonstrating that tralokinumab treatment is associated with improvements in lung function, exacerbations, asthma symptoms and quality of life in subgroups of participants with increased periostin or DPP-4 expression at baseline.

25 Baverel P, White N, Vicini P, Karlsson MO, Agoram B. Dose-exposure-response relationship of the investigational anti-IL-13 monoclonal antibody tralokinumab in patients with severe, uncontrolled asthma. Clin. Pharmacol. Ther. doi:10.1002/cpt.803 (2017) (Epub ahead of print).

26 Baverel PG, Jain M, Stelmach I et al. Pharmacokinetics of tralokinumab in adolescents with asthma: implications for future dosing. Br. J. Clin. Pharmacol. 80(6), 1337-1349 (2015).

27 Panettieri RA Jr, Brightling C, Sjobring U et al. STRATOS 1 and 2: considerations in clinical trial design for a fully human monoclonal antibody in severe asthma. Clin. Invest. (Lond.) 5(8), 701-711 (2015).

-. Describes the study design of STRATOS 1 and STRATOS 2, the pivotal trials in the ATMOSPHERE clinical development program. 
28 Busse WW, Wang M, Gibson J, Gottlow M, Braddock M, Colice G. TROPOS: designing a clinical trial to evaluate the oral corticosteroid-sparing effect of a biologic in severe asthma. Clin. Invest. (Lond.) 5(8), 723-730 (2015).

-. Describes the study design of TROPOS, one of the five trials in the ATMOSPHERE clinical development program.

29 Brightling C, Wang M, Braddock M, Nordenmark L, Gottlow M, Colice G. MESOS: considerations in designing a mechanistic study for a biologic used to treat asthma. Clin. Invest. (Lond.) 5(8), 713-722 (2015).

-. Describes the study design of MESOS, one of the five trials in the ATMOSPHERE clinical development program.

30 Corren J, Lemanske RF, Hanania NA et al. Lebrikizumab treatment in adults with asthma. N. Engl. J. Med 365(12), 1088-1098 (2011).

31 Wenzel S, Castro M, Corren J et al. Dupilumab efficacy and safety in adults with uncontrolled persistent asthma despite use of medium-to-high-dose inhaled corticosteroids plus a long-acting $\beta 2$ agonist: a randomised double-blind placebo-controlled pivotal Phase 2b dose-ranging trial. Lancet 388(10039), 31-44 (2016).

32 Larsen J, Stegger M, Andersen PS et al. Evidence for human adaptation and foodborne transmission of livestock-associated methicillin-resistant Staphylococcus aureus. Clin. Infect. Dis. 63(10), 1349-1352 (2016).

33 Karelina T, Voronova V, Demin O, Colice G, Agoram BM. A mathematical modeling approach to understanding the effect of anti-interleukin therapy on eosinophils. CPT Pharmacometrics Syst. Pharmacol. 5(11), 608-616 (2016).

34 Biomarkers in risk assessment: validity and validation. www.inchem.org/documents/ehc/ehc/ehc222.htm

35 Chiappori A, De Ferrari L, Folli C, Mauri P, Riccio AM, Canonica GW. Biomarkers and severe asthma: a critical appraisal. Clin. Mol. Allergy 13, 20 (2015).

36 Shiobara T, Chibana K, Watanabe T et al. Dipeptidyl peptidase-4 is highly expressed in bronchial epithelial cells of untreated asthma and it increases cell proliferation along with fibronectin production in airway constitutive cells. Respir. Res. 17, 28 (2016).

37 Wagner L, Klemann C, Stephan M, Von Horsten S. Unravelling the immunological roles of dipeptidyl peptidase 4 (DPP4) activity and/or structure homologue (DASH) proteins. Clin. Exp. Immunol. 184(3), 265-283 (2016).

38 Hemken PM, Jeanblanc NM, Rae T et al. Development and analytical performance of a new ARCHITECT automated dipeptidyl peptidase-4 immunoassay. Pract. Lab. Med. 9, 58-68 (2017).

39 Takayama G, Arima K, Kanaji T et al. Periostin: a novel component of subepithelial fibrosis of bronchial asthma downstream of IL-4 and IL-13 signals. J. Allergy Clin. Immunol. 118(1), 98-104 (2006).

40 Johansson MW, Annis DS, Mosher DF. $\alpha(\mathrm{M}) \beta(2)$ integrin-mediated adhesion and motility of IL-5-stimulated eosinophils on periostin. Am. J. Respir. Cell Mol. Biol. 48(4), 503-510 (2013).

41 Blanchard C, Mingler MK, Mcbride M et al. Periostin facilitates eosinophil tissue infiltration in allergic lung and esophageal responses. Mucosal Immunol. 1(4), 289-296 (2008).

42 Noguchi T, Nakagome K, Kobayashi T et al. Periostin upregulates the effector functions of eosinophils. J. Allergy Clin. Immunol. 138(5), 1449-1452, e1445 (2016).

43 Jeanblanc NM, Hemken PM, Datwyler MJ et al. Development of a new ARCHITECT automated periostin immunoassay. Clin. Chim. Acta 464, 228-235 (2017).

44 Dweik RA, Boggs PB, Erzurum SC et al. An official ATS clinical practice guideline: interpretation of exhaled nitric oxide levels (FENO) for clinical applications. Am. J. Respir. Crit Care Med 184(5), 602-615 (2011).

45 Dweik RA, Comhair SA, Gaston B et al. NO chemical events in the human airway during the immediate and late antigen-induced asthmatic response. Proc. Natl Acad. Sci. USA 98(5), 2622-2627 (2001).

46 De Sanctis GT, Maclean JA, Hamada K et al. Contribution of nitric oxide synthases 1, 2, and 3 to airway hyperresponsiveness and inflammation in a murine model of asthma. J. Exp. Med. 189(10), 1621-1630 (1999).

47 Horvath I, Barnes PJ, Loukides S et al. A European Respiratory Society technical standard: exhaled biomarkers in lung disease. Eur. Respir. J. doi:10.1183/13993003.00965-2016 (2017) (Epub ahead of print).

48 Wenzel SE. Emergence of biomolecular pathways to define novel asthma phenotypes. Type-2 immunity and beyond. Am. J. Respir. Cell Mol. Biol. 55(1), 1-4 (2016).

49 Hirano T, Matsunaga K, Sugiura H et al. Persistent elevation of exhaled nitric oxide and modification of corticosteroid therapy in asthma. Respir. Investig. 51(2), 84-91 (2013).

50 Pavord ID, Korn S, Howarth P et al. Mepolizumab for severe eosinophilic asthma (DREAM): a multicentre, double-blind, placebo-controlled trial. Lancet 380(9842), 651-659 (2012).

51 Hanania NA, Korenblat P, Chapman KR et al. Efficacy and safety of lebrikizumab in patients with uncontrolled asthma (LAVOLTA I and LAVOLTA II): replicate, phase 3, randomised, double-blind, placebo-controlled trials. Lancet. Respir. Med. 4(10), $781-796$ (2016).

52 Singh D, Richards D, Knowles RG et al. Selective inducible nitric oxide synthase inhibition has no effect on allergen challenge in asthma. Am. J. Respir. Crit. Care Med. 176(10), 988-993 (2007).

53 Chibana K, Trudeau JB, Mustovich AT et al. IL-13 induced increases in nitrite levels are primarily driven by increases in inducible nitric oxide synthase as compared with effects on arginases in human primary bronchial epithelial cells. Clin. Exp. Allergy 38(6), 936-946 (2008). 
54 Patterson MF, Borish L, Kennedy JL. The past, present, and future of monoclonal antibodies to IL-5 and eosinophilic asthma: a review. J. Asthma Allergy 8, 125-134 (2015).

55 Bel EH, Ten Brinke A. New anti-eosinophil drugs for asthma and COPD: targeting the trait! Chest 152(6), 1276-1282 (2017).

56 Varricchi G, Bagnasco D, Borriello F, Heffler E, Canonica GW. Interleukin-5 pathway inhibition in the treatment of eosinophilic respiratory disorders: evidence and unmet needs. Curr. Opin. Allergy Clin. Immunol. 16(2), 186-200 (2016).

57 De Groot JC, Storm H, Amelink M et al. Clinical profile of patients with adult-onset eosinophilic asthma. ERJ Open Res. 2(2), 00100-2015 (2016).

58 Bleecker ER, Fitzgerald JM, Chanez P et al. Efficacy and safety of benralizumab for patients with severe asthma uncontrolled with high-dosage inhaled corticosteroids and long-acting $\beta 2$-agonists (SIROCCO): a randomised, multicentre, placebo-controlled Phase 3 trial. Lancet 388(10056), 2115-2127 (2016).

59 Fitzgerald JM, Bleecker ER, Nair P et al. Benralizumab, an anti-interleukin-5 receptor $\alpha$ monoclonal antibody, as add-on treatment for patients with severe, uncontrolled, eosinophilic asthma (CALIMA): a randomised, double-blind, placebo-controlled Phase 3 trial. Lancet 388(10056), 2128-2141 (2016).

60 NUCALA $^{\circledR}$ (mepolizumab), prescribing information. GlaxoSmithKline LLC, PA, USA www.gsksource.com/pharma/content/dam/GlaxoSmithKline/US/en/Prescribing_Information/Nucala/pdf/NUCALA-PI-PIL.PDF

61 CINQAIR $^{\circledR}$ (reslizumab), prescribing information. Teva Respiratory, LLC Frazer, PA, USA http://cinqair.com/pdf/PrescribingInformation.pdf

62 Samitas K, Delimpoura V, Zervas E, Gaga M. Anti-IgE treatment, airway inflammation and remodelling in severe allergic asthma: current knowledge and future perspectives. Eur. Respir. Rev. 24(138), 594-601 (2015).

63 Szefler SJ, Wenzel S, Brown R et al. Asthma outcomes: biomarkers. J. Allergy Clin. Immunol. 129(3 Suppl.), S9-S23 (2012).

64 Sly PD, Boner AL, Bjorksten B et al. Early identification of atopy in the prediction of persistent asthma in children. Lancet 372(9643), 1100-1106 (2008).

65 Simpson A, Soderstrom L, Ahlstedt S, Murray CS, Woodcock A, Custovic A. IgE antibody quantification and the probability of wheeze in preschool children. J. Allergy Clin. Immunol. 116(4), 744-749 (2005).

66 Ortega HG, Liu MC, Pavord ID et al. Mepolizumab treatment in patients with severe eosinophilic asthma. N. Engl. J. Med. 371(13), 1198-1207 (2014).

67 Hanania NA, Noonan M, Corren J et al. Lebrikizumab in moderate-to-severe asthma: pooled data from two randomised placebo-controlled studies. Thorax 70(8), 748-756 (2015).

$68 \mathrm{XOLAIR}^{\circledR}$ (omalizumab), prescribing information. Genentech, Inc. A Member of the Roche Group, CA, USA www.gene.com/download/pdf/xolair_prescribing.pdf 

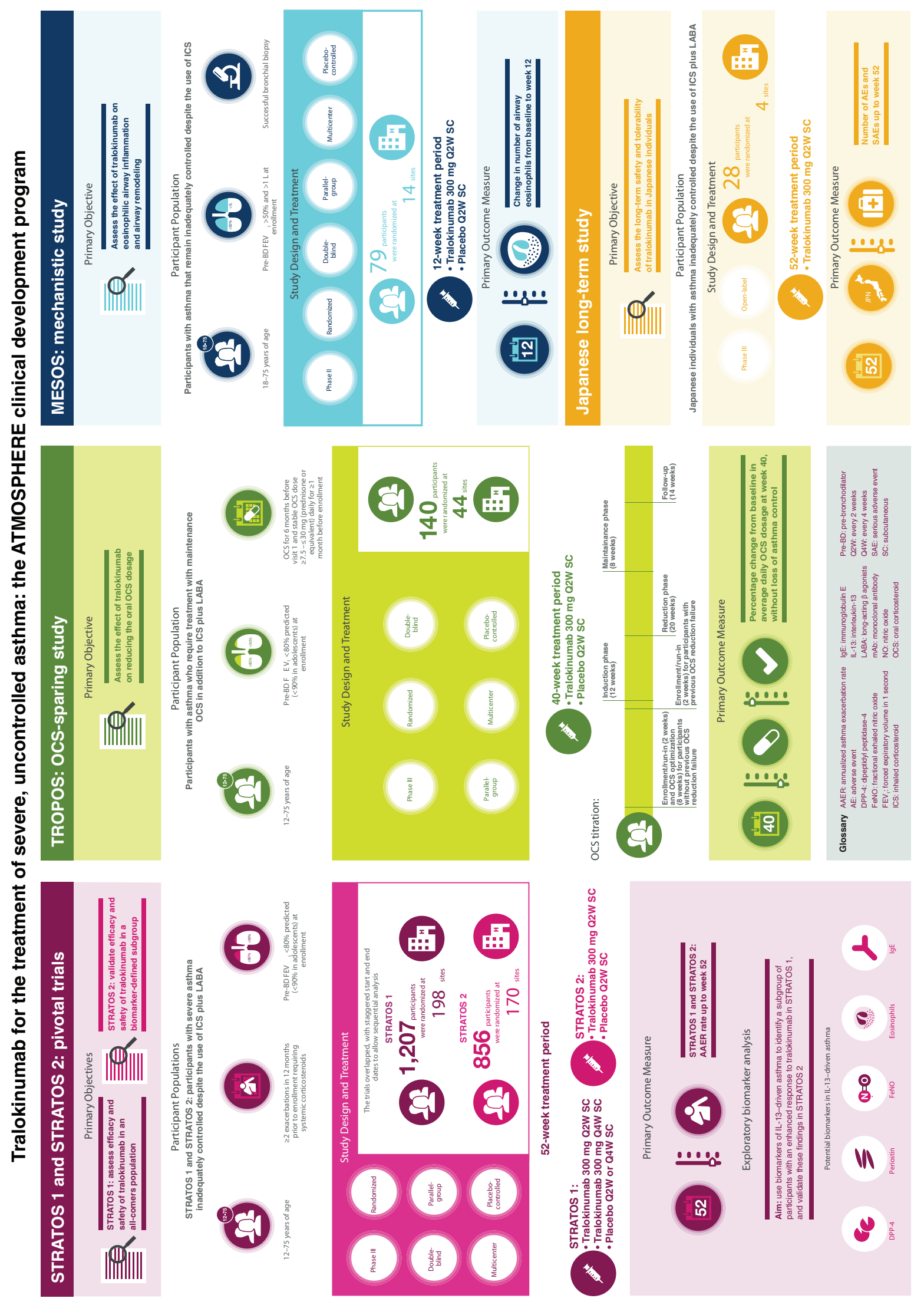

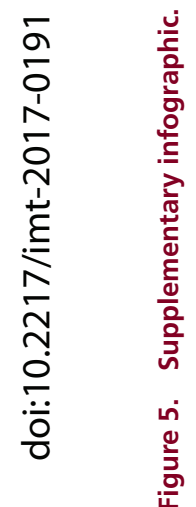

